\title{
Iron Status and Analysis of Efficacy and Safety of Ferric Carboxymaltose Treatment in Patients with Inflammatory Bowel Disease
}

\author{
Florian Beigel $^{\mathrm{a}}$ Beate Löhr ${ }^{\mathrm{a}}$ Rüdiger P. Laubender ${ }^{\mathrm{b}}$ Cornelia Tillack $^{\mathrm{a}}$ \\ Fabian Schnitzler $^{\mathrm{a}}$ Simone Breiteneicher ${ }^{\mathrm{a}} \quad$ Maria Weidinger $^{\mathrm{a}}$ Burkhard Göke $^{\mathrm{a}}$ \\ Julia Seiderer $^{\mathrm{a}}$ Thomas Ochsenkühn ${ }^{\mathrm{a}}$ Stephan Brand ${ }^{\mathrm{a}}$ \\ ${ }^{a}$ Department of Medicine II, University Hospital Munich-Grosshadern, and ${ }^{b}$ Institute of Medical Informatics, \\ Biometry and Epidemiology (IBE), Ludwig Maximilians University, Munich, Germany
}

\author{
Key Words \\ Iron deficiency $\cdot$ Anemia $\cdot$ Anemia of chronic disease . \\ Ferric carboxymaltose $\cdot$ Inflammatory bowel disease . \\ Crohn's disease $\cdot$ Ulcerative colitis $\cdot$ Ferritin $\cdot$ Iron \\ supplementation
}

\begin{abstract}
Background and Aims: We analyzed iron deficiency and the therapeutic response following intravenous ferric carboxymaltose in a large single-center inflammatory bowel disease (IBD) cohort. Methods: 250 IBD patients were retrospectively analyzed for iron deficiency and iron deficiency anemia. A subgroup was analyzed regarding efficacy and side effects of iron supplementation with ferric carboxymaltose. $\boldsymbol{R} \boldsymbol{e}$ sults: In the cohort $(n=250), 54.4 \%$ of the patients had serum iron levels $\leq 60 \mu \mathrm{g} / \mathrm{dl}, 81.2 \%$ had ferritin $\leq 100 \mathrm{ng} / \mathrm{ml}$, and $25.6 \%$ had hemoglobin $(\mathrm{Hb})$ of $\leq 12 \mathrm{~g} / \mathrm{dl}$ (females) or $\leq 13$ $\mathrm{g} / \mathrm{dl}$ (males). In the treatment subcohort ( $\mathrm{n}=80$ ), $83.1 \%$ of the patients had iron $\leq 60 \mu \mathrm{g} / \mathrm{dl}, 90.4 \%$ had ferritin $\leq 100$ $\mathrm{ng} / \mathrm{ml}$, and $66.7 \%$ had $\mathrm{Hb} \leq 12 / 13 \mathrm{~g} / \mathrm{dl}$ before ferric carboxymaltose treatment. After a median dose of $500 \mathrm{mg}$ ferric carboxymaltose, $74.7 \%$ of the patients reached iron $>60 \mu \mathrm{g} / \mathrm{dl}$, $61.6 \%$ had ferritin $>100 \mathrm{ng} / \mathrm{ml}$, and $90.7 \%$ reached $\mathrm{Hb}>12 / 13$ $\mathrm{g} / \mathrm{dl}$ at follow-up $(\mathrm{p}<0.0001$ for all parameters vs. pretreatment values). The most frequent adverse event was a tran-
\end{abstract}

sient increase of liver enzymes with male gender as risk factor ( $p=0.008$, OR 8.62, 95\% Cl 1.74-41.66). Conclusions: Iron deficiency and anemia are frequent in IBD patients. Treatment with ferric carboxymaltose is efficious, safe and well tolerated in iron-deficient IBD patients.

Copyright $\odot 2011$ S. Karger AG, Basel

\section{Introduction}

Iron deficiency is common in patients with inflammatory bowel disease (IBD), affecting up to $80 \%$ of all patients and leading to anemia in approximately one third of all IBD patients $[1,2]$. In IBD, iron deficiency is caused by dietary restrictions, iron malabsorption due to active disease or intestinal blood loss. Moreover, the chronic intestinal inflammation in IBD patients leads to an upregulation of proinflammatory cytokines (e.g. IL-1 $\beta$, IL-6) and consecutively hepcidin, which results in an impaired

Parts of this work were presented as a poster at the 6th Congress of the European Crohn's and Colitis Organization (ECCO) in Dublin 2011 and published in J Crohns Colitis 2011;5(1):S116.

This work contains parts of the unpublished medical degree thesis of B. Löhr.

\section{KARGER}

Fax +41613061234 E-Mail karger@karger.ch www.karger.com
(C) 2011 S. Karger AG, Basel

0012-2823/12/0851-0047\$38.00/0

Accessible online at:

www.karger.com/dig
Stephan Brand, MD

Department of Medicine II, University Hospital Munich-Grosshadern

Ludwig Maximilians University Munich, Marchioninistrasse 15

DE-81377 Munich (Germany)

Tel. +49897095 2291, E-Mail stephan.brand@med.uni-muenchen.de 
intestinal iron uptake from the gut and sequestering of iron in the reticuloendothelial system. Hepcidin inhibits iron uptake by interaction with the iron export protein ferroportin, which is located on the cell surface of hepatocytes, macrophages and the basolateral membrane of enterocytes [3-5]. This mechanism represents a major cause of iron deficiency and associated anemia of chronic disease in IBD and other chronic inflammatory diseases [6].

For the treatment of iron deficiency anemia, the preferred route of iron supplementation in IBD is intravenous, although many patients would also respond to oral iron. However, intravenous iron is more effective, better tolerated, and improves the quality of life to a greater extent than oral iron supplements. Absolute indications for intravenous iron include severe anemia $(\mathrm{Hb}<10 \mathrm{~g} / \mathrm{dl})$, intolerance, or inappropriate response to oral iron, severe intestinal disease activity, concomitant therapy with erythropoietin, or patient preference. Oral iron supplements can be used if absolute indications for intravenous iron therapy are not met and the response and tolerance should be monitored, and treatment should be changed to intravenous iron preparations if necessary. Several clinical trials clearly demonstrated that intravenous iron supplementation has better efficacy, tolerability and longterm response than oral iron treatment [7-9]. Furthermore, in animal models, there is evidence that oral iron supplements lead to oxidative stress in the gut and may aggravate disease activity $[10,11]$. These observations have also been made in IBD patients $[12,13]$.

Ferric carboxymaltose (Ferinject ${ }^{\circledR}$; Vifor Pharma, Glattbrugg, Switzerland) is a novel, optimized iron formulation for intravenous application. It is a water-soluble, macromolecular iron hydroxy-complex consisting of polynuclear iron (III) hydroxide with a molecular weight of $150 \mathrm{kDa}$. Efficacy of ferric carboxymaltose has been demonstrated in various studies, including treatment of anemia in chronic kidney disease, chronic heart failure, post-partum anemia and IBD [14-19]. In the latter trial, ferric carboxymaltose was non-inferior to oral administered ferrous sulfate in terms of hemoglobin $(\mathrm{Hb})$ change over 12 weeks. However, there was superiority in providing a faster $\mathrm{Hb}$ response, a higher increase in iron stores, and a better patient tolerance [14]. There are additional advantages of ferric carboxymaltose in clinical practice. For instance, high doses of iron can be administered in a short infusion time ( $\max .1,000 \mathrm{mg}$ as infusion in $15 \mathrm{~min}$; up to $200 \mathrm{mg}$ as i.v. bolus). Even the risk of side effects regarding toxicity and hypersensitivity seems to be lower compared with other intravenous iron formulations [20].
Therefore, ferric carboxymaltose has been used in our outpatient clinic for the treatment of iron deficiency and iron deficiency anemia since its approval in Germany in November 2007.

Given that all large trials using ferric carboxymaltose were pharmaceutical company sponsored resulting in potential conflicts of interest, we aimed in this study without pharmaceutical sponsoring to analyze the iron status in IBD patients and to investigate the efficacy and safety of ferric carboxymaltose for iron supplementation in IBD patients in clinical practice in a large single-center cohort.

\section{Materials and Methods}

\section{Study Cohort}

Medical and laboratory records of all patients, who visited our IBD center for the first time in $2008(\mathrm{n}=250)$, were analyzed for iron parameters, including serum iron, serum ferritin and $\mathrm{Hb}$ values. Iron values of $\leq 60 \mu \mathrm{g} / \mathrm{dl}$ and ferritin $\leq 100 \mathrm{ng} / \mathrm{ml}$ were considered as clinically relevant and defined as pathologic in this study. According to the WHO definition, anemia is defined as a decline in blood hemoglobin to a concentration of $<12 \mathrm{~g} / \mathrm{dl}(120$ $\mathrm{g} / \mathrm{l})$ in women and of $<13 \mathrm{~g} / \mathrm{dl}(130 \mathrm{~g} / \mathrm{l})$ in men. Therefore, these values were considered pathologic in this study.

Out of this cohort, we identified 80 patients who were treated with ferric carboxymaltose at least for one dose of $100 \mathrm{mg}$. Indications for ferric carboxymaltose treatment were serum iron levels of $\leq 60 \mu \mathrm{g} / \mathrm{dl}$ and $\mathrm{Hb} \leq 12 / 13 \mathrm{~g} / \mathrm{dl}$, or iron $\leq 60 \mu \mathrm{g} / \mathrm{dl}$, ferritin $\leq 100 \mathrm{ng} / \mathrm{ml}$ and $\mathrm{Hb} \leq 12 / 13 \mathrm{~g} / \mathrm{dl}$. Patients were also included into the study when serum iron was $\leq 60 \mu \mathrm{g} / \mathrm{dl}$ and ferritin $>100$ $\mathrm{ng} / \mathrm{ml}$ if there was presence of inflammation (elevated CRP and/ or elevated leukocyte count without previous or ongoing steroid treatment).

Based on the protocol of the FERGIcor trial [21], the initial ferric carboxymaltose dose was at least $500 \mathrm{mg}$. Only in 1 patient with allergies against other intravenous iron supplements was an initial dose of $100 \mathrm{mg}$ ferric carboxymaltose chosen. The total ferric carboxymaltose dose (range $100-7,500 \mathrm{mg}$ ) was dependent on the severity of the initial iron deficiency and iron deficiency anemia. Efficacy regarding increase of $\mathrm{Hb}$, iron and ferritin and side effects of ferric carboxymaltose treatment, including laboratory values (blood count, liver enzymes and LDH), were monitored. Patients were followed up for a median time interval of 20 weeks. After this study interval, patients with relapsing iron deficiency or iron deficiency anemia (as defined in this study) received further treatment with ferric carboxymaltose.

\section{Statistical Analysis}

Data were summarized by adequate measures of location and spread for continuous variables and by proportions for discrete variables. Adequate two-sample tests for continuous data ( $t$ test, Mann-Whitney U test) and for discrete data ( $\chi^{2}$ tests, Fisher's exact test) were used. For the prediction of liver enzyme elevation, we used a logistic regression model where predictors were selected from a potential set of predicting variables [serum iron, ferritin, 
serum CRP, age, duration of IBD, gender, type of IBD (Crohn's disease or ulcerative colitis), body mass index (BMI), concomitant treatment with immunosuppressive agents or anti-TNF antibodies] by relying on the multivariate fraction polynomials (mfp) algorithm which simultaneously allows for testing non-linear relationships of continuous predictors and the outcome. To identify patient groups with the greatest risk for anemia, we used a logistic regression model similar to the previous one including all patients with iron deficiency anemia (excluding patients with macrocytic anemia) and anemia $\mathrm{Hb}$ levels $\leq 12 / 13 \mathrm{~g} / \mathrm{dl}$ as outcome predictor. The corresponding set of potential predictors was serum iron, ferritin, serum CRP, age, gender, type of IBD, disease duration, BMI, concomitant treatment with immunosuppressives or anti-TNF antibodies and MCV. For predicting ferritin, we built a linear regression model by relying on the $\mathrm{mfp}$ algorithm where the potential predictors gender, iron, $\mathrm{CRP}, \mathrm{Hb}$ and $\mathrm{BMI}$ were considered. To satisfy the normality assumption, we took the natural logarithm of ferritin for modeling purposes. Using the same method, we developed a model for predicting $\mathrm{Hb}$ from the potential predictors ferritin, CRP, iron and gender. Based on the final linear regression model for $\mathrm{Hb}$, we were able to construct prediction intervals for an individual case's $\mathrm{Hb}$ value given the values of the selected predictors. Further, the assumptions of the regression models were evaluated by using graphically based residual analyses. All statistical tests were performed two-sided, a $p$ value of $<0.05$ was considered as statistically significant. All statistical analyses were performed by using $\mathrm{R}$ (version 2.12.1) and PASW Statistics 17.0.

\section{Results}

\section{Prevalence of Iron Deficiency and Iron Deficiency}

\section{Anemia in IBD Patients}

Iron parameters and $\mathrm{Hb}$ levels of $250 \mathrm{IBD}$ patients, who visited our IBD center for the first time from January 2008 to December 2008, were analyzed. Crohn's disease was diagnosed in $67.6 \%(n=169)$, ulcerative colitis in $32.4 \%(n=81) ; 55.6 \%(n=139)$ were females, $44.4 \%(n=$ 111) were males. There was a high prevalence of iron deficiency among these patients. Serum iron levels of $\leq 60$ $\mu \mathrm{g} / \mathrm{dl}$ were seen in 136 patients (54.4\%), 203 patients $(81.2 \%)$ had ferritin levels $\leq 100 \mathrm{ng} / \mathrm{ml}$ and 64 patients (25.6\%) were anemic with Hb levels $\leq 12 / 13 \mathrm{~g} / \mathrm{dl}$ (table 1 ). Iron deficiency anemia with iron values $\leq 60 \mu \mathrm{g} / \mathrm{dl}$, ferritin levels $\leq 100 \mathrm{ng} / \mathrm{ml}$ and Hb levels $\leq 12 / 13 \mathrm{~g} / \mathrm{dl}$ were found in 44 patients (17.6\%). In this study, we defined $\mathrm{Hb}$ levels $\leq 12 / 13 \mathrm{~g} / \mathrm{dl}$ as anemia of chronic disease, when concomitantly serum ferritin levels were $\geq 100 \mathrm{ng} / \mathrm{ml}$ and CRP serum levels were $>0.5 \mathrm{mg} / \mathrm{dl}$. Only 9 patients (3.6\%) met these criteria.

\section{Predictors of Microcytic Anemia in IBD Patients}

Multivariate logistic regression analyses demonstrated a stronger effect of serum iron than ferritin levels on
Table 1. Demographic and clinical characteristics of the whole study cohort $(\mathrm{n}=250)$

\begin{tabular}{lc}
\hline Demographic and clinical characteristics & \multicolumn{1}{l}{ Patients } \\
\hline Male/female & $111 / 139(44.4 / 55.6)$ \\
Median age, years & $36.9(18-74)$ \\
CD/UC & $169 / 81(67.6 / 32.4)$ \\
Median duration of disease, years & $8(2-38)$ \\
Iron $\leq 60 \mu \mathrm{g} / \mathrm{dl}$ & $136(54.4)$ \\
Ferritin $\leq 100 \mathrm{ng} / \mathrm{ml}$ & $203(81.2)$ \\
Hb levels $\leq 12 / 13 \mathrm{~g} / \mathrm{dl}$ & $64(25.6)$ \\
$\mathrm{CRP}>0.5 \mathrm{mg} / \mathrm{dl}$ & $142(56.8)$ \\
Anti-TNF- $\alpha$ antibody-treated patients & $146(58.4)$ \\
Patients treated with & \\
Immunosuppressives & $179(71.6)$ \\
Systemic corticosteroids & $56(22.4)$
\end{tabular}

Values are numbers with percentages or range in parentheses.

the prediction of microcytic anemia. This analysis revealed (logarithmized) serum iron $\left(\mathrm{p}<2.38 \times 10^{-10}\right)$ with an odds ratio (OR) of 0.03 [95\% confidence interval (CI) 0.01-0.09] and (logarithmized) ferritin ( $\mathrm{p}=1.25 \times$ $\left.10^{-4}\right)$ with an OR of 0.29 (95\% CI 0.15-0.55) as risk factors for the development of microcytic anemia.

Ferritin levels are modulated by the degree of inflammation (as reflected by CRP values). Similarly, in our study cohort, ferritin levels were significantly influenced by the (logarithmized) serum CRP levels $(p=0.005)$. A final linear regression model applied to our IBD study population $(n=250)$ statistically confirmed the effect of iron $(\mathrm{p}<0.001)$ on $\mathrm{Hb}$. As expected, gender also showed statistically significant differences in predicting Hb levels $(\mathrm{p}<0.001)$ with higher Hb values in males. Additionally the $\mathrm{mfp}$ algorithm revealed a non-linear relationship between iron and $\mathrm{Hb}$ as shown in figure 1. For predicting the mean $\mathrm{Hb}$ value based on serum iron level (labeled in the formula as 'iron') and gender, the linear predictor of the final regression model can be used which is given by:

$$
\begin{aligned}
& \text { Male IBD patients: } \mathrm{Hb}=17.45-19.07 \times 1 / \sqrt[2]{\text { iron }} \\
& \text { Female IBD patients: } \mathrm{Hb}=17.45-19.07 \times 1 / \sqrt[2]{\text { iron }}-0.8
\end{aligned}
$$

The corresponding 50 and $95 \% \mathrm{Hb}$ prediction intervals based on serum iron levels are shown in figure $2 \mathrm{a}$ and b separately for male and female IBD patients. The percentiles in these figures may be helpful for deciding when intravenous iron supplementation should be started; however, considering the high variability of serum iron levels, these figures cannot replace more reliable param- 


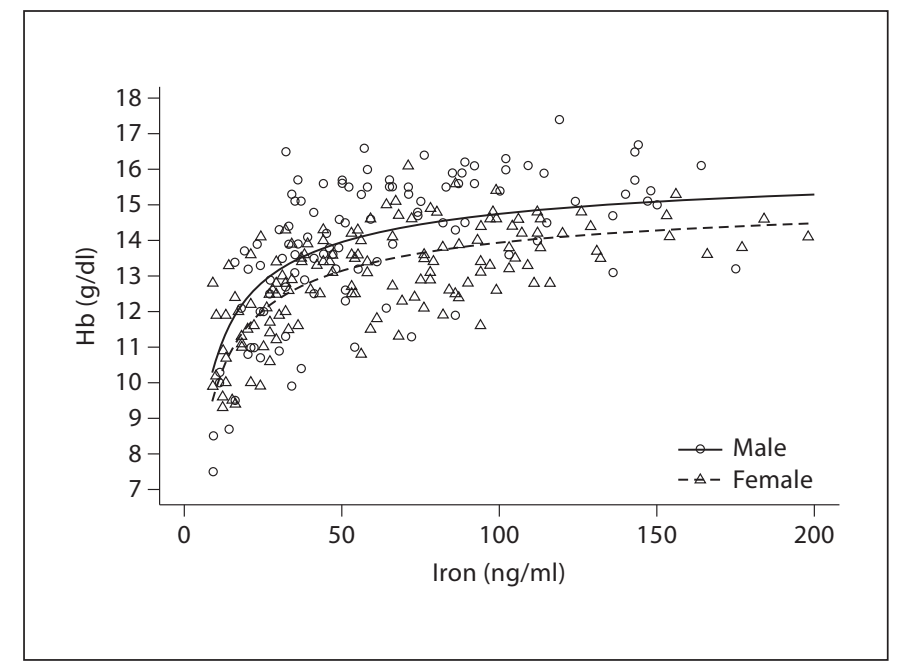

Fig. 1. Scatter plot of $\mathrm{Hb}$ values versus serum iron levels stratified by gender. The predicted mean values based on the final linear regression model are shown as lines (solid line: males; dashed line: females).
Table 2. Demographic and clinical characteristics of the subcohort with ferric carboxymaltose treatment $(n=80)$

\begin{tabular}{lc}
\hline Demographic and clinical characteristics & Patients \\
\hline Male/female, n (\%) & $35 / 45(43.8 / 56.2)$ \\
Median age, years (range) & $35.2(18-70)$ \\
CD/UC, $\mathrm{n}(\%)$ & $49 / 31(61.3 / 38.7)$ \\
Median duration of disease, years (range) & $7(2-30)$ \\
Median dose of ferric carboxymaltose, mg & \\
(range) & $500(100-7,500)$ \\
Median follow-up, weeks (SD) & $20(12)$ \\
Iron $\leq 60 \mu \mathrm{g} / \mathrm{dl}, \mathrm{n}(\%)$ & $59(83.1)$ \\
Ferritin $\leq 100 \mathrm{ng} / \mathrm{ml}, \mathrm{n}(\%)$ & $66(90.4)$ \\
Hb levels $\leq 12 / 13$ g/dl, n (\%) & $50(66.7)$ \\
CRP $>0.5 \mathrm{mg} / \mathrm{dl}, \mathrm{n}(\%)$ & $39(48.8)$ \\
Anti-TNF- $\alpha$ antibody-treated patients, $\mathrm{n}(\%)$ & $59(73.7)$ \\
Patients treated with & \\
$\quad$ Immunosuppressives, $\mathrm{n}(\%)$ & $46(57.5)$ \\
$\quad$ Systemic corticosteroids, $\mathrm{n}(\%)$ & $4(5.0)$
\end{tabular}

$\mathrm{CD} / \mathrm{UC}=$ Crohn's disease/ulcerative colitis.

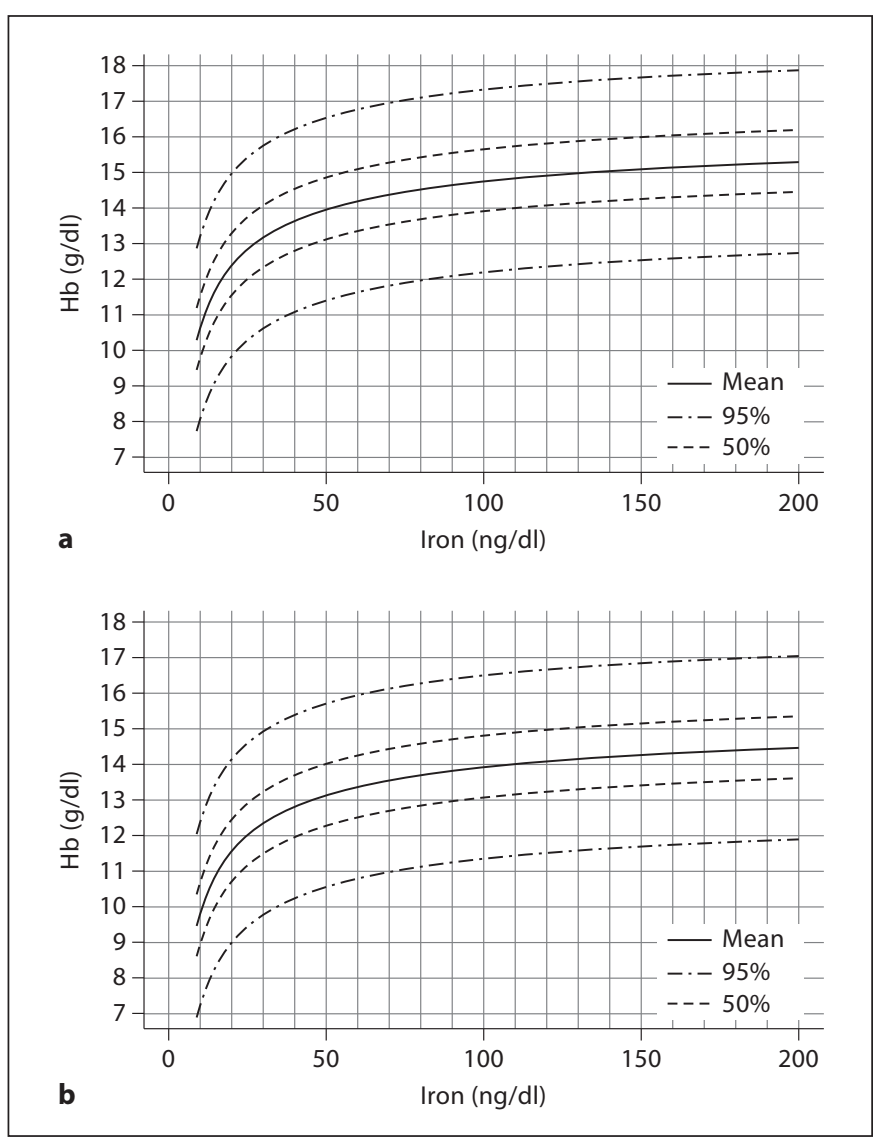

Fig. 2. Mean values and 50 and $95 \%$ prediction intervals for $\mathrm{Hb}$ based on serum iron levels for males (a) and females (b). eters of measuring the iron status such as transferrin saturation or soluble transferrin receptor.

\section{Efficacy of Ferric Carboxymaltose Treatment}

Out of the whole patient cohort $(n=250), 80$ patients were treated with ferric carboxymaltose and were followed up for a median of 20 weeks (range 1-60). In this subgroup, $61.3 \%$ had Crohn's disease $(n=49), 38.7 \%$ ulcerative colitis $(n=31), 56.2 \%(n=45)$ were females and $43.8 \%(\mathrm{n}=35)$ were males. Total cumulative ferric carboxymaltose doses during the follow-up period ranged from 100 to 7,500 mg (see details in the Materials and Methods section). The median dose was $500 \mathrm{mg}$ (table 2).

Seventy-one patients had complete data on iron parameters and $\mathrm{Hb}$ levels to be analyzed for efficacy of ferric carboxymaltose treatment. Before treatment with ferric carboxymaltose, $83.1 \%$ of the patients $(\mathrm{n}=59)$ had serum iron levels of $\leq 60 \mu \mathrm{g} / \mathrm{dl}$, while only $16.9 \%$ of the patients had normal serum iron levels. In the follow-up period and after a median dose of $500 \mathrm{mg}$ ferric carboxymaltose, $74.6 \%(n=53)$ reached the target serum iron level of $>60 \mu \mathrm{g} / \mathrm{dl}$ (fig. 3a; $\mathrm{p}<0.001$ ) versus pretreatment levels.

Ferritin levels were analyzed in 73 patients treated with ferric carboxymaltose. Before treatment with ferric carboxymaltose, $90.4 \%$ of the patients $(n=66)$ had serum ferritin $\leq 100 \mathrm{ng} / \mathrm{ml}$, while only $9.6 \%$ had ferritin values $>100 \mathrm{ng} / \mathrm{ml}$. In the follow-up period and after a median 


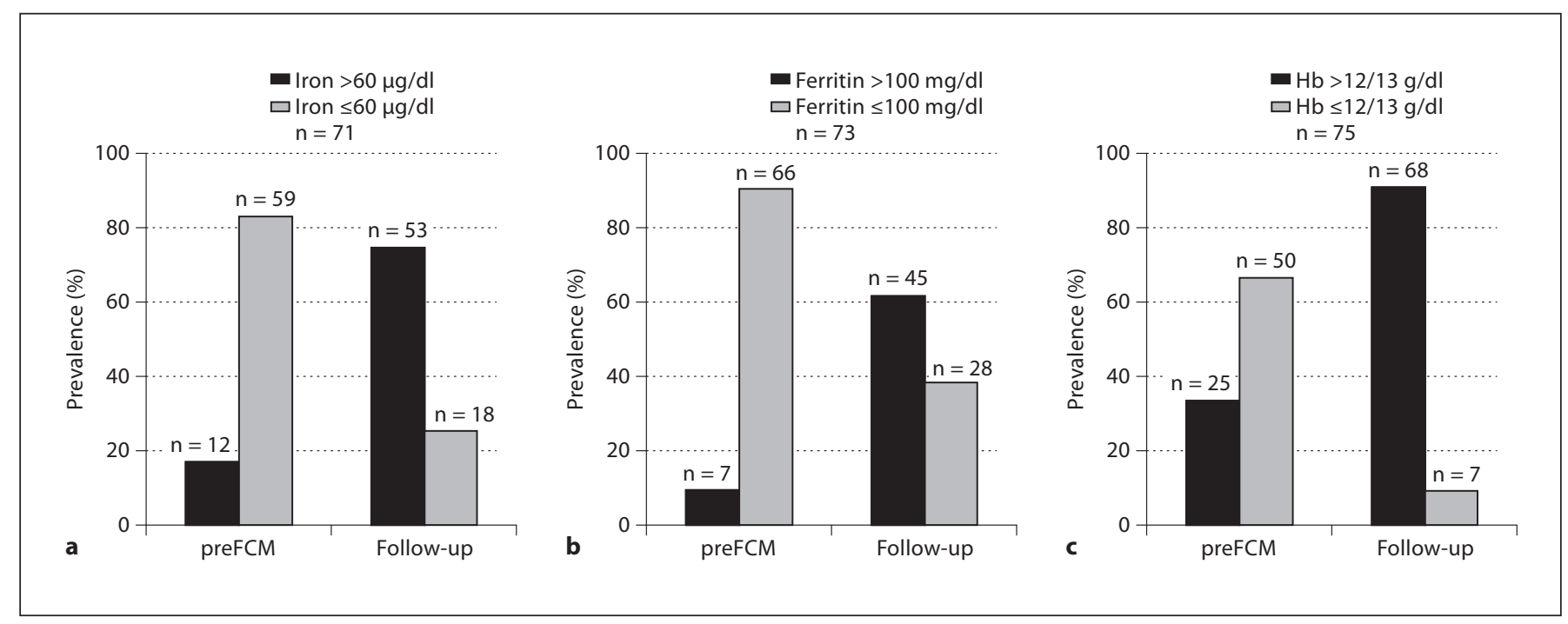

Fig. 3. Percentages of patients with iron values $>60$ and $\leq 60 \mu \mathrm{g} / \mathrm{dl}$ (a), ferritin values $>100$ and $\leq 100 \mathrm{mg} / \mathrm{dl}$ (b), and $\mathrm{Hb}$ values $>12 / 13$ and $\leq 12 / 13 \mathrm{~g} / \mathrm{dl}$ (c) before ferric carboxymaltose treatment (preFCM) and at follow-up after a median dose of $500 \mathrm{mg}$ ferric carboxymaltose.

dose of $500 \mathrm{mg}$ ferric carboxymaltose, $61.6 \%(\mathrm{n}=45)$ reached the ferritin target value of $>100 \mathrm{ng} / \mathrm{ml}$ (fig. 3b; $\mathrm{p}<0.001)$ versus pretreatment levels.

Seventy-five patients were analyzed regarding changes of $\mathrm{Hb}$ levels under ferric carboxymaltose treatment. Before treatment, $66.7 \%$ of the patients $(n=50)$ had Hb levels $\leq 12 / 13 \mathrm{~g} / \mathrm{dl}$, while only one third $(33.3 \% ; \mathrm{n}=25)$ had normal $\mathrm{Hb}$ levels. After a median dose of $500 \mathrm{mg}$ ferric carboxymaltose, $90.7 \%(n=68)$ reached $\mathrm{Hb}$ levels $>12 / 13$ $\mathrm{g} / \mathrm{dl}$ in the follow-up period (fig. $3 \mathrm{c} ; \mathrm{p}<0.001$ ) versus pretreatment levels.

\section{Side Effects of Ferric Carboxymaltose}

During the median follow-up period of 20 weeks, $17.5 \%$ of the patients $(n=14)$ developed side effects associated with ferric carboxymaltose treatment. The most frequent adverse event was a transient increase of liver enzymes (APT and/or ALT) of greater than two times the upper normal limit, which occurred in 12 patients $(15.0 \%)$ and completely resolved at follow-up. One patient complaint about headaches after the infusion (1.25\%) and 1 patient developed feet edema (1.25\%; table 3$)$.

\section{Predictors of Abnormal Liver Function Tests in Ferric \\ Carboxymaltose-Treated IBD Patients}

Given that a transient increase of liver enzymes was the most frequent side effect of ferric carboxymaltose treatment within the follow-up period, we aimed to iden-
Table 3. Side effects in the ferric carboxymaltose treatment group $(\mathrm{n}=80)$

\begin{tabular}{lc}
\hline Side effect & Patients, $\mathrm{n}(\%)$ \\
\hline Increase of liver enzymes & $12(15)$ \\
Headache & $1(1.25)$ \\
Feet edema & $1(1.25)$ \\
\hline
\end{tabular}

tify predictors for the development of increased liver enzymes using multivariate analysis and pretreatment parameters ( $\gamma$-GT, Hb, serum iron levels, ferritin, CRP) and age, gender, type of IBD (Crohn's disease or ulcerative colitis), BMI, concomitant treatment with immunosuppressives or anti-TNF antibodies and cumulative dose ferric carboxymaltose as predictor variables. Multivariate analyses revealed only male gender $(\mathrm{p}=0.008$, OR 8.621, 95\% CI 1.74-41.66) as risk factor for the development of increased liver enzymes.

\section{Discussion}

In our single-center cohort, we found a high prevalence of iron deficiency and anemia, which is consistent with findings of other studies in IBD patients $[1,2,22]$. Given that anemia is the most common systemic compli- 
cation in IBD patients, treatment of iron deficiency, which is the major cause for anemia in these patients, is an important goal in IBD treatment [23-25]. In our patient cohort, iron, ferritin and $\mathrm{Hb}$ restorage was achieved with a median dose of $500 \mathrm{mg}$ ferric carboxymaltose in the majority of the patients with very low side effects. The most frequent side effect was a transient increase of liver enzymes, particularly in male patients.

The present study was limited by the lack of sufficient data for most patients regarding transferrin saturation and soluble transferrin receptor, which are important laboratory parameters of iron status in patients with systemic inflammation, in which serum ferritin levels may be increased despite iron deficiency [26]. Similarly, in our IBD cohort, ferritin levels were significantly modulated by the serum CRP levels. Using a linear regression model, we demonstrate a non-linear relationship between iron and $\mathrm{Hb}$. In addition, we provide $\mathrm{Hb}$ percentile curves based on the serum iron levels which may be a helpful tool for deciding when intravenous iron supplementation should be started in IBD patients. However, we have to acknowledge that serum iron levels are influenced by a number of factors and are much less reliable than transferrin saturation or soluble transferrin receptor.

In the past, oral iron supplementation has been commonly used in IBD patients. While oral iron supplementation is suitable and effective in patients without malabsorption, side effects like nausea and constipation and insufficient restorage of iron and $\mathrm{Hb}$ levels limit the use of oral iron formulations. In addition, several studies demonstrated that oral iron induces oxidative stress in the gut and aggravates inflammation [11, 27]. In IBD patients, there is often the need for high iron doses due to very low iron stores, resulting from chronic bleeding or inflammatory conditions $[2,28,29]$.

For administration of high iron doses, most approved intravenous formulations like low or high molecular weight iron dextran, iron sucrose and sodium ferric gluconate have to be given several times with long infusion times to reach target iron/Hb values. In addition, several of these agents, particularly high molecular weight iron dextran, may have side effects like severe anaphylactic reactions.

Ferric carboxymaltose, a novel iron formulation, was approved for treatment of iron deficiency and iron deficiency anemia in Europe in 2007. Several studies in patients with different disease entities demonstrated improved symptoms, functional capacity and quality of life, while the side-effect profile was acceptable $[14,15,30,31]$.
In this study, the initial ferric carboxymaltose dose was based on data of the randomized controlled FERGIcor trial [21], in which all patients received initially at least $500 \mathrm{mg}$ ferric carboxymaltose. This simpler ferric carboxymaltose-based dosing regimen showed better efficacy and compliance compared with the Ganzoni-calculated iron sucrose dose regimen [21]. Our results support the data of the FERGIcor trial [21] and demonstrate that in the majority of patients encountered in daily practice, a single $500 \mathrm{mg}$ ferric carboxymaltose infusion is sufficient to treat iron deficiency and mild iron deficiency anemia.

Although comparative studies analyzing efficacy are rare, there are data regarding side effects. In a clinical trial including patients with chronic kidney disease undergoing hemodialysis, a lower proportion of ferric carboxymaltose than iron sucrose recipients experienced at least one drug-related adverse event (5 vs. $10.2 \%$ : p value not reported). However, there were no statistically significant differences between the groups regarding other parameters of drug tolerability [32]. The tolerability and safety profile of ferric carboxymaltose has been summarized in an abstract which included ten studies with $>2,000$ patients treated with ferric carboxymaltose [33]. According to this summary, $15.3 \%$ of ferric carboxymaltose recipients and $26.1 \%$ of oral ferrous sulfate recipients reported at least one drug-related adverse event. Headache, the most frequently reported adverse event related to ferric carboxymaltose, occurred in $<3 \%$ of patients of both treatment groups which is consistent with our study, in which only 1 patient (1.2\%) complained about headaches after therapy. Rash and local injection site reactions were more common in patients treated with ferric carboxymaltose, whereas gastrointestinal adverse events (particularly constipation and nausea) were more frequently reported in ferrous sulfate recipients across the trials [20]. The very recently released data of the FERGIcor trial [21] demonstrate that hyperferritinemia and transient hypophosphatemia may be an additional side effect of ferric carboxymaltose treatment.

Toxicity of iron treatment is well known. The concentration of non-transferrin-bound iron/free iron has been shown to correlate with an increase in the incidence of adverse events following intravenous administration of iron sucrose [34]. It has been proposed that non-transferrin-bound iron may catalyze a number of reactions that in turn lead to oxidative stress and membrane damage.

As a mechanism of iron deficiency, hepcidin represents a key regulator of iron metabolism. When using po- 
tent anti-inflammatory drugs like anti-TNF antibodies, hepcidin may be downregulated. This in turn leads to an increased iron mobilization and uptake from the gut [35], which may result in a functional increase in iron deficiency. To treat the higher demand for iron in this situation, transitional high-dose iron supplementation is necessary [36]. Hence, by the early use of highly effective anti-inflammatory therapeutics (i.e. anti-TNF antibodies) in IBD patients with the goal of mucosal healing, long-term incidence of iron deficiency may decrease in the future [37].

In summary, iron deficiency and anemia are very common in IBD patients. As we demonstrated in our study, ferric carboxymaltose is a very efficient and well-tolerated therapy in IBD patients. In this cohort, transient liver enzyme elevations were the most common side effect. A single dose of $500 \mathrm{mg}$ ferric carboxymaltose was sufficient to normalize $\mathrm{Hb}$ levels in the majority of iron-deficient IBD patients. Limitations of this study include its retrospective nature and the lack of transferrin saturation levels in the majority of patients. Further prospective studies with larger patient cohorts are needed to clarify the advantages and cost-effectiveness of ferric carboxymaltose compared to other intravenous iron formulations.

\section{Acknowledgements}

S. Brand is supported by grants from the Deutsche Forschungsgemeinschaft (DFG; BR 1912/6-1), the Else Kröner-Fresenius-Stiftung (Else Kröner Exzellenzstipendium 2010; 2010 EKES.32) and by grants from the Ludwig Maximilians University Munich (LMUM; Excellence Initiative - Investment Fund 2008 and FöFoLe Program 2007 and 2008). F. Beigel is supported by grants from LMUM (FöFoLe Program 2008) and the DFG (BE 4490/2-1). F. Schnitzler is supported by grants from LMUM (FöFoLe Program 2009). J. Seiderer was supported by grants from LMUM (FöFoLe Program, Nr. 422; Habilitationsstipendium, LMUExcellent), the Robert Bosch Foundation and the Else Kröner-Fresenius-Stiftung (Else Kröner-Memorial Stipendium 81/08//EKMS08/01).

\section{Disclosure Statement}

The authors have no conflicts of interest to declare.

\section{References}

1 Wilson A, Reyes E, Ofman J: Prevalence and outcomes of anemia in inflammatory bowel disease: a systematic review of the literature. Am J Med 2004;116(suppl 7A):44S-49S.

2 Gasche C, Lomer MC, Cavill I, Weiss G: Iron, anaemia, and inflammatory bowel diseases. Gut 2004:53:1190-1197.

3 Nemeth E, Rivera S, Gabayan V, Keller C, Taudorf S, Pedersen BK, Ganz T: IL-6 mediates hypoferremia of inflammation by inducing the synthesis of the iron regulatory hormone hepcidin. J Clin Invest 2004;113: 1271-1276.

4 Ganz T: Hepcidin, a key regulator of iron metabolism and mediator of anemia of inflammation. Blood 2003;102:783-788.

5 Nemeth E, Tuttle MS, Powelson J, Vaughn MB, Donovan A, Ward DM, Ganz T, Kaplan J: Hepcidin regulates cellular iron efflux by binding to ferroportin and inducing its internalization. Science 2004;306:2090-2093.

6 Fleming MD: The regulation of hepcidin and its effects on systemic and cellular iron metabolism. Hematology Am Soc Hematol Educ Program 2008;151-158.
7 Schroder O, Mickisch O, Seidler U, de Weerth A, Dignass AU, Herfarth H, Reinshagen M, Schreiber S, Junge U, Schrott M, Stein J: Intravenous iron sucrose versus oral iron supplementation for the treatment of iron deficiency anemia in patients with inflammatory bowel disease - a randomized, controlled, open-label, multicenter study. Am J Gastroenterol 2005;100:2503-2509.

8 Erichsen K, Ulvik RJ, Nysaeter G, Johansen J, Ostborg J, Berstad A, Berge RK, Hausken $\mathrm{T}$ : Oral ferrous fumarate or intravenous iron sucrose for patients with inflammatory bowel disease. Scand J Gastroenterol 2005;40: 1058-1065.

9 Qunibi WY, Martinez C, Smith M, Benjamin J, Mangione A, Roger SD: A randomized controlled trial comparing intravenous ferric carboxymaltose with oral iron for treatment of iron deficiency anaemia of non-dialysis-dependent chronic kidney disease patients. Nephrol Dial Transplant 2011;26: 1599-1607.

10 Srigiridhar K, Nair KM, Subramanian R, Singotamu L: Oral repletion of iron induces free radical mediated alterations in the gastrointestinal tract of rat. Mol Cell Biochem 2001;219:91-98.
11 Carrier J, Aghdassi E, Platt I, Cullen J, Allard JP: Effect of oral iron supplementation on oxidative stress and colonic inflammation in rats with induced colitis. Aliment Pharmacol Ther 2001;15:1989-1999.

12 Erichsen K, Hausken T, Ulvik RJ, Svardal A, Berstad A, Berge RK: Ferrous fumarate deteriorated plasma antioxidant status in patients with Crohn disease. Scand J Gastroenterol 2003;38:543-548.

13 De Silva AD, Tsironi E, Feakins RM, Rampton DS: Efficacy and tolerability of oral iron therapy in inflammatory bowel disease: a prospective, comparative trial. Aliment Pharmacol Ther 2005;22:1097-1105.

14 Kulnigg S, Stoinov S, Simanenkov V, Dudar LV, Karnafel W, Garcia LC, Sambuelli AM, D'Haens G, Gasche C: A novel intravenous iron formulation for treatment of anemia in inflammatory bowel disease: the ferric carboxymaltose (Ferinject ${ }^{\circledR}$ ) randomized controlled trial. Am J Gastroenterol 2008;103: 1182-1192. 
15 Van Wyck DB, Martens MG, Seid MH, Baker JB, Mangione A: Intravenous ferric carboxymaltose compared with oral iron in the treatment of postpartum anemia: a randomized controlled trial. Obstet Gynecol 2007;110: 267-278.

16 Breymann C, Gliga F, Bejenariu C, Strizhova $\mathrm{N}$ : Comparative efficacy and safety of intravenous ferric carboxymaltose in the treatment of postpartum iron deficiency anemia. Int J Gynaecol Obstet 2008;101:67-73.

17 Tagboto S, Cropper L, Turner J, Pugh-Clarke $\mathrm{K}$ : The efficacy of a single dose of intravenous ferric carboxymaltose (Ferinject ${ }^{\circledR}$ ) on anaemia in a pre-dialysis population of chronic kidney disease patients. J Ren Care 2009;35:18-23.

18 Anker SD, Colet JC, Filippatos G, Willenheimer R, Dickstein K, Drexler H, Luscher TF, Mori C, von Eisenhart Rothe B, Pocock S, Poole-Wilson PA, Ponikowski P: Rationale and design of Ferinject ${ }^{\circledR}$ assessment in patients with IRon deficiency and chronic Heart Failure (FAIR-HF) study: a randomized, placebo-controlled study of intravenous iron supplementation in patients with and without anaemia. Eur J Heart Fail 2009; 11:1084-1091.

19 Anker SD, Comin Colet J, Filippatos G, Willenheimer R, Dickstein K, Drexler H, Luscher TF, Bart B, Banasiak W, Niegowska J, Kirwan BA, Mori C, von Eisenhart Rothe B, Pocock SJ, Poole-Wilson PA, Ponikowski P: Ferric carboxymaltose in patients with heart failure and iron deficiency. N Engl J Med 2009; 361:2436-2448.

20 Qunibi WY: The efficacy and safety of current intravenous iron preparations for the management of iron-deficiency anaemia: a review. Arzneimittelforschung 2010;60: 399-412.

21 Evstatiev R, Marteau P, Iqbal T, Khalif IL, Stein J, Bokemeyer B, Chopey IV, Gutzwiller FS, Riopel L, Gasche C: FERGIcor, a randomized controlled trial on ferric carboxymaltose for iron deficiency anemia in inflammatory bowel disease. Gastroenterology 2011; 141:846-853.e1-2.
22 Wilson A, Yu HT, Goodnough LT, Nissenson AR: Prevalence and outcomes of anemia in rheumatoid arthritis: a systematic review of the literature. Am J Med 2004;116(suppl 7A):50S-57S.

23 Gasche C: Complications of inflammatory bowel disease. Hepatogastroenterology 2000; 47:49-56.

24 Pizzi LT, Weston CM, Goldfarb NI, Moretti D, Cobb N, Howell JB, Infantolino A, Dimarino $\mathrm{AJ}$, Cohen S: Impact of chronic conditions on quality of life in patients with inflammatory bowel disease. Inflamm Bowel Dis 2006; 12:47-52.

25 Wells CW, Lewis S, Barton JR, Corbett S: Effects of changes in hemoglobin level on quality of life and cognitive function in inflammatory bowel disease patients. Inflamm Bowel Dis 2006;12:123-130.

26 Stein J, Hartmann F, Dignass AU: Diagnosis and management of iron deficiency anemia in patients with IBD. Nat Rev Gastroenterol Hepatol 2010;7:599-610.

27 Werner T, Wagner SJ, Martinez I, Walter J, Chang JS, Clavel T, Kisling S, Schuemann K, Haller D: Depletion of luminal iron alters the gut microbiota and prevents Crohn's disease-like ileitis. Gut 2011;60:325-333.

28 Lomer MC, Kodjabashia K, Hutchinson C, Greenfield SM, Thompson RP, Powell JJ: Intake of dietary iron is low in patients with Crohn's disease: a case-control study. $\mathrm{Br}$ Nutr 2004;91:141-148.

29 Semrin G, Fishman DS, Bousvaros A Zholudev A, Saunders AC, Correia CE, Nemeth E, Grand RJ, Weinstein DA: Impaired intestinal iron absorption in Crohn's disease correlates with disease activity and markers of inflammation. Inflamm Bowel Dis 2006; 12:1101-1106.
30 Kociol RD, Newby LK: Ferric carboxymaltose improved symptoms and quality of life in patients with chronic heart failure and iron deficiency. Ann Intern Med 2010;152:JC4JC5.

31 Szczech LA, Bregman DB, Harrington RA, Morris D, Butcher A, Koch TA, Goodnough LT, Wolf M, Onken JE: Randomized evaluation of efficacy and safety of ferric carboxymaltose in patients with iron deficiency anaemia and impaired renal function (REPAIR-IDA): rationale and study design. Nephrol Dial Transplant 2010;25:23682375.

32 Schaefer RM, Khasabov NN, Todorov NG, et al: The efficacy and safety of intravenous ferric carboxymaltose compared to iron sucrose in haemodialysis patients with iron deficiency anaemia. 45th Congress of the European Renal Association and the European Dialysis and Transplant Association, Stockholm, May 10-13, 2008, abstract Mp375.

33 Qunibi M: Safety and tolerability profile of ferric carboxymaltose (FCM), a new high dose intravenous iron, across ten multi-center clinical trials. 40th Annual Meeting of the American Society of Nephrology, San Francisco, November 2-5, 2007, poster abstract.

34 Chandler G, Harchowal J, Macdougall IC: Intravenous iron sucrose: establishing a safe dose. Am J Kidney Dis 2001;38:988-991.

35 Fleming RE, Sly WS: Hepcidin: A putative iron-regulatory hormone relevant to hereditary hemochromatosis and the anemia of chronic disease. Proc Natl Acad Sci USA 2001;98:8160-8162

36 Katsanos K, Cavalier E, Ferrante M, Van Hauwaert V, Henckaerts L, Schnitzler F, Katsaraki A, Noman M, Vermeire S, Tsianos EV, Rutgeerts P, Chapelle JP, Van Assche G: Intravenous iron therapy restores functional iron deficiency induced by infliximab. J Crohns Colitis 2007;1:97-105.

37 Domenech E, Manosa M, Masnou H, Navarro M, Garcia-Planella E, Bernal I, Gassull MA: Infliximab for the treatment of chronic anemia in Crohn's disease. Am J Gastroenterol 2005; 100:496 